\title{
Health Literacy and Depression in the Context of Home Visitation
}

\author{
Sandra A. Smith • Elizabeth J. Moore
}

Published online: 26 November 2011

(C) The Author(s) 2011. This article is published with open access at Springerlink.com

\begin{abstract}
We explored health literacy in parents as an underlying construct that develops through social interaction and reflection and involves an array of skills that enable a parent to manage personal and child health and healthcare. We hypothesized that depression impairs health literacy and impedes efforts to promote health literacy through home visitation. We analyzed an AHRQ/NIH database of 2,572 parent/child dyads compiled in a 2006-2008 quasi-experimental six-site nationwide study using multiple waves of measurement and a matched comparison group. Cohort families participated in home visitation programs augmented to develop parents' reflective skills. Visitors monitored depression, health- and healthcare-related practices, and surrounding family conditions at baseline and 6-month intervals for up to 36 months using the Life Skills Progression instrument. We examined differences in initial depression ratings for demographic subgroups and explored patterns of change in health literacy among depressed versus not-depressed parents. Correlation analysis showed that at each of four
\end{abstract}

Preliminary findings were reported at the National Conference of the Association of Maternal Child Health Programs, February 2008; the American College of Physicians and Institute of Medicine National Conference on New Directions in Health Literacy, November 2008; and at the Health Literacy Annual Research Conference, October 2010. The abstract was presented at the Health Literacy Annual Research Conference, October 2011.

\section{S. A. Smith $(\square)$}

Department of Health Services, University of Washington; and Center for Health Literacy Promotion, Seattle, WA, USA

e-mail: sandras@uw.edu

\section{E. J. Moore}

Applied Inference, Seattle, WA, USA assessments better depression scores were consistently and positively correlated with use of information and services $(\mathrm{r}=21-22, P<.001)$ and with self-management of personal and child health $(\mathrm{r}=42-49, P<.001)$. Overall, parents made significant improvements in health literacy $(P<.001)$. As expected, depressed parents demonstrated lower baseline health literacy scores than not-depressed parents; however, they achieved greater gains $(P<.001)$. While depression is linked with lower parental health literacy, after 1 year of enhanced home visitation, vulnerable parents were better able to manage personal and family health and healthcare, especially if depressed. Enhanced home visitation could be an effective channel to develop health literacy as a life skill, and to improve depression.

Keywords Health literacy - Depression .

Community health services $\cdot$ Home visitation

\section{Parental Health Literacy and Depression in the Context of Home Visitation}

Parental health literacy is a determinant of child health and a source of health disparities [1]. Most research has framed health literacy as reading ability in a medical setting and focused on low health literacy as a cognitive deficit in patients [2]. Studies have shown that most US adults, including parents, have limited health literacy [3]; that is, large proportions performed poorly on health-related literacy tasks such as filling out an insurance form. Associations are established between low health literacy and adverse healthcare outcomes [4]. However, the pathway linking reading skills and outcomes is unclear, especially the link between parents' reading ability and child health outcomes [4]. To increase understanding beyond the 
current focus on reading ability in a medical setting and elucidate the range of possible responses, it is increasingly important to reconsider the meaning of health literacy [5].

Commonly used measures of health literacy are reading and comprehension tests using medical terms and documents. Better measures that reflect the reality of health literacy in people's lives are needed to assess health literacy [2] and identify its association with maternal mental health [1].

Health literacy intervention studies remain rare [4], especially community-based interventions customized to diverse low-literacy populations [1] and interventions focused on improving skills [6]. We found no studies testing home visitation for its effect on parental health literacy and no previous attempts to directly improve advanced health literacy skills with parents of children to age three.

\section{Parental Depression}

Depression impairs approximately 7.5 million parents in the United States each year and may put 15 million children at risk for adverse health outcomes [7]. Parental depression can be triggered or exacerbated by pregnancy and postpartum stresses [8] up to 1 year after childbirth [9]. If untreated, depression can persist for years [10, 11]. Parental depression is associated with negative child health impacts extending into adulthood [9, 12]. Depression remains underrecognized and undertreated, especially in socioeconomically disadvantaged, medically underserved populations, contributing to the persistence of health disparities. There has been little examination of depression in parents beyond the immediate postpartum period [13]. A few studies link low literacy with depression; however, the association is not well understood [14, 15]. Depression and low health literacy are thought to be significant barriers to child [14, 16] and adult health services [15, 17], and to home visitation services [18].

Home visitation is a preventive intervention that supports families and healthy development of children. Service populations are characterized by high rates of depression [10] and low literacy [17]. Home visitation can be used to help those at risk for low health literacy increase healthpromoting behaviors, decision making, goal setting, and self management [1, 14]. Promising approaches have been developed to treat depression in the context of home visitation, but standard home visitation services alone are insufficient to bring about substantial improvement in depressive symptoms [10]. Visitors and supervisors identify depression as a significant barrier to providing home visitation services [19]. It remains unclear whether depression reduces the effectiveness of home visitation or if mothers in home visitation programs show gains despite depression [18].

This study is groundbreaking in several ways. Following the lead of literacy scholars and integrating behavioral health theory, we reframed health literacy as a life skill required to navigate modern society, including health systems and everyday choices that influence health [20]. In this frame, health literacy skills and needs evolve over the life course, and early parenting presents an optimal time to develop health literacy skills that can benefit entire families across their lifetimes. Developing parental health literacy is an empowerment strategy to increase parents' control over their health, their ability to seek information and to take responsibility for family health [21]. Thus we aimed to promote parental health literacy as a personal asset. This makes health literacy an outcome of health education and skills development efforts [22], as well as a factor that might influence clinical outcomes. We adapted a definition of maternal health literacy [23] based on the World Health Organization's definition of health literacy [24]: the cognitive and social skills which determine the motivation and ability of mothers (parents) to gain access to, understand, and use information in ways that promote and maintain their health and that of their children.

In this sociocultural model, health literacy involves an array of skills, plus motivation and action. It operates as a latent construct that cannot be directly measured but is estimated through contextual factors such as healthcare participation, adoption of healthy behaviors and maintenance of safe environments [25]. These factors are not health literacy in themselves, but demonstrate what health literacy enables parents to do with the information available to them.

To measure change in health literacy, we re-purposed the Life Skills Progression (LSP), an instrument commonly used to evaluate effects of home visitation services on parent/child outcomes [26]. The LSP instrument is approved for evaluation of progress to federal benchmarks of effectiveness in Maternal, Infant and Early Childhood Home Visiting (MIECHV) Programs [27] (described under "Methods"). In addition to health literacy scales, the LSP includes indicators of parental depression and surrounding family conditions. The data allowed us to examine differences in initial depression ratings for demographic subgroups, assess changes in parental depression over 18 months in enhanced home visitation, and explore patterns of change in health literacy among depressed versus not-depressed parents.

The most important finding of this study is that in enhanced home visitation both depressed and not-depressed parents achieved significant improvements in management of personal and child health and healthcare, demonstrating improved health literacy. Depressed parents made greater gains in health literacy than their not-depressed counterparts. 


\section{Methods}

For reading ease we use the terms depressed and depression. It should be noted that about half of parents rated as depressed were not clinically diagnosed, but demonstrated depressive symptoms.

Programs and Intervention

The study population consisted of 2,572 parent/child dyads who participated in one of seven home visitation programs in five states. Figure 1 shows the number of families served at each site.

The sites are broadly representative of national networks of home visitation programs including evidence-based models (Healthy Families America, National Healthy Start, Early Head Start, Parents as Teachers), and promising models (Strengthening Families, CHIP of Virginia, and a telephonic case management service for isolated families in rural New Mexico). Program models differ in their specific goals and approaches, service areas and populations, staffing models, and use of supplemental curricula. The participating programs are differentiated from most other programs in their model by their specific intent to promote parental health literacy and reflective functioning, and by their routine use of the Beginnings Guides Life Skills Development Curriculum including the LSP.

Parents' (in a few cases, grandparents') ages ranged from 13 to 68 years [average 25.4 years $(\mathrm{SD}=7.4$ years $)$. Subject children were ages $0-3$ years. About one-third (32\%) of the study population were African American, 29\% Caucasian, 18\% Hispanic/Latino, 2\% other ethnicities, and $20 \%$ unknown or missing ethnicities. The families were Medicaid-eligible and/or at risk for child maltreatment. At the sites, high school completion rates at intake ranged from 33 to $53 \%$. Screening estimated $30-36 \%$ of the cohort had reading skill $\leq$ sixth grade.

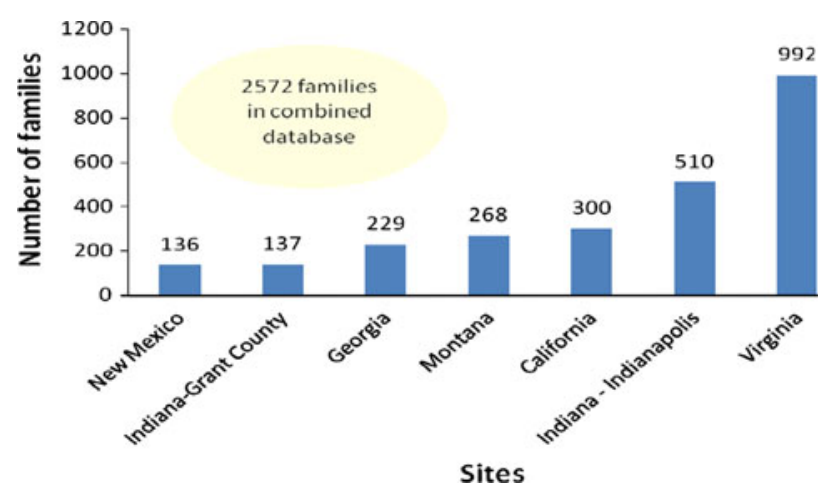

Fig. 1 Number of parent-child pairs followed at each site
Since 2004, a number of home visitation programs have obtained training and curriculum [28] to integrate into their usual activities strategies for developing parents' reflective skills as the foundation for both health literacy [22] and reflective functioning [29]. Training included use of the LSP to guide reflective practice, tailor interventions for individual families, monitor progress, and evaluate parent/ child outcomes. To demonstrate that the strategies could be integrated into existing services, we recruited programs serving racially/ethnically different populations and representing various models of home visitation (e.g. Early Head Start, National Healthy Start, Parents as Teachers, Healthy Families America) to contribute their LSP data for secondary analysis. These data were combined for AHRQ/ NICHD Grant \#R03HD055618-02, resulting in at least one and up to seven observations for 2,572 parent/child dyads. Of these parents, 2,409 were rated on the LSP depression measure at baseline and 704 parents at six sites also had an assessment 12-18 months after intake.

\section{Data Collection}

The visitors collected data on parental depression, healthand healthcare-related practices, and surrounding family conditions at baseline and 6-month intervals for up to 36 months using the LSP. The LSP summarizes the visitors' formal and informal assessments, observations and interviews over the previous 6-month period. The LSP rates parents' progress toward developing 35 interrelated lifeskills in five categories: Relationships, Education and Employment, Health and Medical Care, Mental Health and Substance Use, Basic Essentials. Each item uses a Likert scale producing a score from .5 (dysfunctional) to 5 (optimally functional) with an assigned target range indicating adequate to optimal functioning. The LSP captures the complexity of the family/home context where most health information is processed, most health choices are made, and most preventive actions and treatments are carried out. The data enabled us to estimate parents' health literacy skill by their use of information and services in context, and to explore the interactions of multiple factors that support or hinder health literacy.

\section{Depression Measure}

Table 1 provides detail on the LSP depression item and shows baseline scores. Because several screening instruments are available [30-32], the LSP depression item focuses on identifying the incidence of depression and progress to recovery [26]. Ratings are based on self-reports, in most cases using a screening instrument, further informed by the home visitor's observations and interviews, and, at some sites, review of the medical record. The 
Table 1 Distribution of parents on the LSP depression scale at initiation of service

\begin{tabular}{|c|c|c|}
\hline Score & Description & Number (\%) \\
\hline .5 & \multirow{2}{*}{$\begin{array}{l}\text { Recurrent chronic depression with } \\
\text { suicidal attempts/thoughts; severe } \\
\text { problem with activities of daily living } \\
\text { (ADL), parenting and insight/ } \\
\text { perception }\end{array}$} & \\
\hline 1 & & $8(.3 \%)$ \\
\hline 1.5 & \multirow{2}{*}{$\begin{array}{l}\text { Recurrent chronic depression without } \\
\text { suicidal attempts/thoughts; moderate } \\
\text { problem with ADL, parenting and } \\
\text { insight/perception }\end{array}$} & $4(.2 \%)$ \\
\hline 2 & & $44(1.8 \%)$ \\
\hline 2.5 & \multirow{2}{*}{$\begin{array}{l}\text { Recent postpartum or situational } \\
\text { depression; some problem with ADL, } \\
\text { parenting and insight/perception }\end{array}$} & $20(.8 \%)$ \\
\hline 3 & & $183(7.6 \%)$ \\
\hline 3.5 & \multirow{2}{*}{$\begin{array}{l}\text { Manages or controls depression with } \\
\text { treatment and/or medications or has } \\
\text { recovered; adequate ADL, parenting } \\
\text { and insight/perception }\end{array}$} & $60(2.5 \%)$ \\
\hline 4 & & $284(11.8 \%)$ \\
\hline 4.5 & \multirow{2}{*}{ Not depressed; optimistic } & $143(5.9 \%)$ \\
\hline 5 & & $1,663(69 \%)$ \\
\hline
\end{tabular}

baseline LSP is completed after the second visit and considers about 2 hours of in-home observation, intake interviews, assessments and referrals. Subsequent ratings are made every 6 months and at close of service. This method improves on most previous studies which rely solely on self-report of depressive symptoms, typically in the previous week [10]. Periodic rating of symptoms continuously monitored in context depicts the scope and change in depression.

\section{Health Literacy Measures}

To estimate health literacy as a life skill that enables parents to participate in healthcare and manage personal and child health, we used the LSP measures of information seeking, use of health services and community resources, health behaviors, parenting practices, and maintenance of safe environments. Two scales were derived from the LSP to assess different aspects of parental health literacy [33].

The Healthcare Literacy (HcL) Scale combines nine LSP item scores to rate parents' use of information and healthcare services for parent and child, demonstrating skills that pertain to interactions with the healthcare system. Alternative labels for such skills are "medical literacy" [34], "patient health literacy" [35] or "clinical health literacy" [36]. The Selfcare Literacy (ScL) Scale combines seven LSP item scores to rate parents' management of personal and child health at home, demonstrating skills that pertain to everyday choices, actions, practices and behaviors that influence family health. (See Table 3 for a list of items comprising the health literacy scales.) Other authors [34] refer to these skills as "health literacy" differentiated

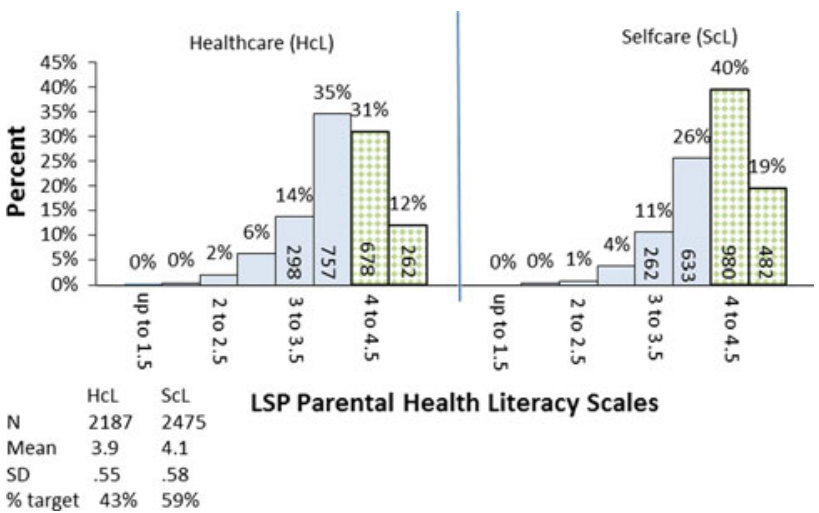

Fig. 2 Distribution of initial healthcare literacy and selfcare literacy scores

from "medical literacy." Logical analysis and expert review were used to establish the content validity [37] of the health literacy scales. The scales show good internal consistency [Cronbach's alpha $=.74(\mathrm{HcL})$ and $.76(\mathrm{ScL})$ ] and strong criterion validity using several measures of parental and family functioning [33]. Figure 2 shows the distribution of $\mathrm{HcL}$ and $\mathrm{ScL}$ at baseline, with the two bars to the right representing the parents in the "target" range for these scales.

\section{Matched Comparison Group}

Analysis proceeded in two phases. Phase 1 used Analysis of Variance (ANOVA) with repeated measures to examine change in overall depression scores and overall health literacy scores, from baseline to $12-18$ months. A limitation of this approach is that observed changes could be due to ensuing community events or to maturation. To address these alternative explanations, we created a within-cohort "comparison" group of parents who first entered home visitation after their age-matched "experimental" counterparts had received services for 12-18 months. In addition to age, parents were matched on service site, sex, race, reading level, and timing of observation. These "comparison parents" baseline scores represent what one would expect the "experimental parents" scores to be at the same age without effective home visitation services. If the home visitation services are effective, on average with all else being equal, after 12-18 months of effective home visitation services, the "experimental parents" should have more positive scores than their matched comparisons who are new to home visitation. Results of this comparison were similar to the results of the repeated measures analysis, suggesting that improvements are unlikely to be explained by maturation or community events.

Phase 2 explored the relationship between depression and health literacy using: (a) correlation between concurrent depression score and health literacy scale scores; and 
(b) a mixed design ANOVA to examine the pattern of change in health literacy for parents rated as depressed versus not-depressed at intake.

\section{Results}

Average baseline depression scores were not significantly different for "comparison" and "experimental" parents $[4.6$ vs. $4.6 ; \mathrm{F}(1,1,370)=.2 ; \mathrm{ns}]$. The depression measure was dichotomized to depressed (treated or not, 25\%) and not-depressed $(75 \%)$. A two-way frequency distribution revealed that of parents with a 12-18 month assessment, $21 \%$ were rated depressed at intake, compared with $28 \%$ of those without a follow-up assessment (presumed dropouts) $\left(\chi^{2}(1)=7.2 ; P<.01\right)$.

Among those who remained in service for 12 months, repeated measures ANOVA revealed a significant improvement in overall depression scores $(\mathrm{F}(1,703)=4 ; P<.05)$, as well as $\operatorname{HcL}(\mathrm{F}(1,668)=48 ; P<.001)$ and $\operatorname{ScL}(\mathrm{F}(1,688)=$ $57 ; P<.001)$. Figure 3 separates the parents in the depressed group into two sub groups: treated/medicated and not treated/medicated. This figure shows that $11.9 \%$ were assessed as depressed and untreated at intake, down to $8.5 \%$ 12-18 months later.

Table 2 shows that depression correlated with both HcL and $\mathrm{ScL}$ at each time point with the greatest correlation between depression and ScL. That is, parents with more positive depression scores also tended to have more positive $\mathrm{HcL}$ and $\mathrm{ScL}$ scores, while parents with less positive depression scores tended to have less positive $\mathrm{HcL}$ and ScL scores.

\section{Effect of Depression on Change in Health Literacy}

Table 3 presents the items comprising the two health literacy scales. For each item, the first four columns show the percentage of parents in the depressed category at intake who were in the target range for that item at each observation. The next four columns show the same percentage for parents in the not-depressed category at intake. The table illustrates that, overall, less depressed parents better managed personal and child health and healthcare. The differences between depressed and not-depressed parents are greater at baseline than after 12-18 months of enhanced home visitation, suggesting that enhanced home visitation may buffer the negative impact of depression on health literacy.

A mixed model ANOVA with repeated measures was used to examine whether the change in parents' $\mathrm{HcL}$ and ScL over $12-18$ months in enhanced home visitation is influenced by depression status. Figure 4 shows an overall significant increase in $\mathrm{HcL}$ across three time points from baseline to $12-18$ months. It also shows that those with depression had significantly lower HcL scores overall. Further, on average, depressed parents demonstrated less initial HcL than those without depression, and they showed greater gains, almost catching up to their not-depressed counterparts in $\mathrm{HcL}$.

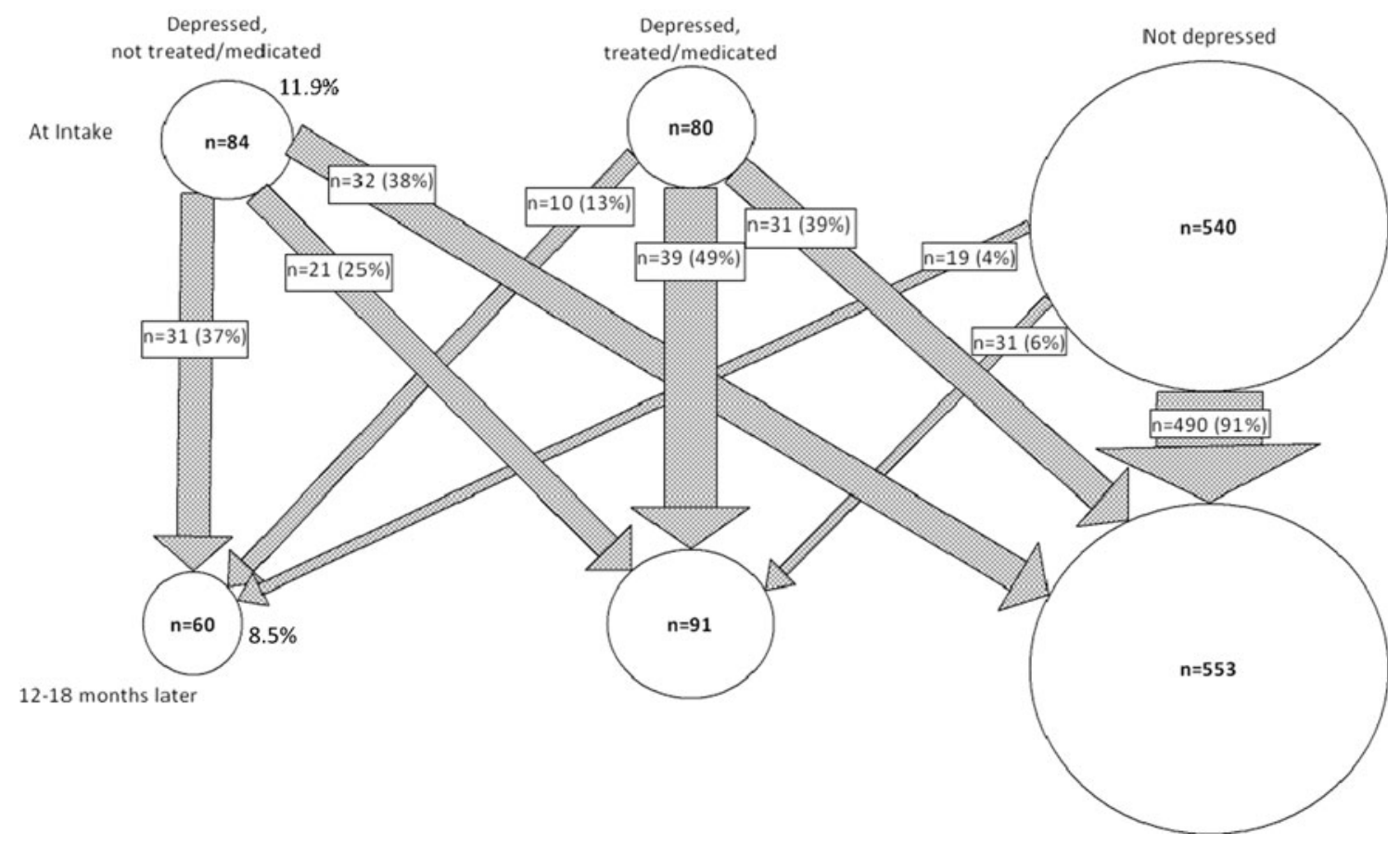

Fig. 3 Movement between depression categories 
Table 2 Correlation between $\mathrm{HcL} / \mathrm{ScL}$ and depression over a year of home visitation

\begin{tabular}{|c|c|c|c|c|c|c|}
\hline Depression/suicide & Baseline HcL & 6 months HcL & 12-18 months HcL & Baseline ScL & 6 months ScL & 12-18 months ScL \\
\hline \multirow[t]{2}{*}{ Baseline depression } & $\mathrm{r}=.21^{\mathrm{F}}$ & $\mathrm{r}=.12^{\mathrm{T}}$ & $r=.08$ & $r=.42^{\mathrm{F}}$ & $r=.36^{\mathrm{F}}$ & $\mathrm{r}=.23^{\mathrm{F}}$ \\
\hline & $\mathrm{n}=2,123$ & $\mathrm{n}=983$ & $\mathrm{n}=681$ & $\mathrm{n}=2,388$ & $\mathrm{n}=994$ & $\mathrm{n}=675$ \\
\hline \multirow[t]{2}{*}{6 months depression } & $\mathrm{r}=.18^{\mathrm{T}}$ & $\mathrm{r}=.22^{\mathrm{F}}$ & $\mathrm{r}=.13^{¥}$ & $\mathrm{r}=.40^{\mathrm{F}}$ & $r=.49^{\mathrm{F}}$ & $\mathrm{r}=.31^{\mathrm{F}}$ \\
\hline & $\mathrm{n}=930$ & $\mathrm{n}=999$ & $\mathrm{n}=533$ & $\mathrm{n}=1,002$ & $\mathrm{n}=1,009$ & $\mathrm{n}=531$ \\
\hline \multirow[t]{2}{*}{ 12-18 months depression } & $\mathrm{r}=.12^{¥}$ & $\mathrm{r}=.16^{¥}$ & $\mathrm{r}=.22^{\mathrm{T}}$ & $\mathrm{r}=.38^{\mathrm{T}}$ & $\mathrm{r}=.44^{\mathrm{T}}$ & $r=.43^{T}$ \\
\hline & $\mathrm{n}=645$ & $\mathrm{n}=530$ & $\mathrm{n}=684$ & $\mathrm{n}=683$ & $\mathrm{n}=532$ & $\mathrm{n}=681$ \\
\hline
\end{tabular}

$¥ \mathrm{p}<.01 ;{ }^{\mp} \mathrm{p}<.001$

Table 3 Percentage of parents in target range on health literacy items by initial depression rating

\begin{tabular}{|c|c|c|c|c|c|c|c|c|}
\hline & \multicolumn{4}{|c|}{ Depressed (\%) } & \multicolumn{4}{|c|}{ Not depressed (\%) } \\
\hline & Baseline & 6 months & 12 months & 18 months & Baseline & 6 months & 12 months & 18 months \\
\hline \multicolumn{9}{|l|}{ Selfcare literacy measures } \\
\hline Attitudes to pregnancy & 19 & 23 & & & 23 & 26 & & \\
\hline Support of development & 41 & 45 & 58 & 62 & 61 & 67 & 73 & 76 \\
\hline Safety & 75 & 78 & 81 & 87 & 90 & 92 & 92 & 92 \\
\hline Use of resources & 54 & 63 & 70 & 66 & 69 & 73 & 78 & 79 \\
\hline Substance use/abuse & 85 & 88 & 91 & 94 & 96 & 98 & 98 & 98 \\
\hline Tobacco use & 63 & 63 & 58 & 67 & 83 & 79 & 80 & 81 \\
\hline \multicolumn{9}{|c|}{ Healthcare literacy measures } \\
\hline Use of information & 62 & 69 & 78 & 74 & 78 & 80 & 82 & 83 \\
\hline Prenatal care & 67 & 76 & & & 73 & 78 & & \\
\hline Parent sick care & 57 & 58 & 60 & 57 & 70 & 67 & 70 & 68 \\
\hline Family planning & 49 & 60 & 62 & 72 & 65 & 73 & 78 & 78 \\
\hline Child well care & 88 & 89 & 94 & 94 & 94 & 94 & 97 & 94 \\
\hline Child sick care & 86 & 87 & 93 & 93 & 93 & 93 & 93 & 96 \\
\hline Child dental care & 53 & 58 & 67 & 72 & 61 & 64 & 67 & 67 \\
\hline Child immunization & 94 & 95 & 98 & 97 & 95 & 96 & 96 & 98 \\
\hline Basic health insurance & 58 & 68 & 72 & 73 & 64 & 69 & 72 & 72 \\
\hline
\end{tabular}

Figure 5 shows a similar pattern for selfcare literacy. Overall, parents achieved significant improvement in ScL with enhanced home visitation. Depressed parents scored lower on ScL overall and made greater gains in ScL than did their not-depressed counterparts.

Analysis with the matched comparison group showed that parents who had been in enhanced home visitation for a year had significantly higher $\mathrm{HcL}$ scores (4.1 vs. 3.9: $\mathrm{F}(1$, $1310)=16 ; P<.001)$ and $\mathrm{ScL}$ scores $(4.3$ vs. $4.1: \mathrm{F}(1$, $1324)=25 ; P<.001)$ than their age-matched controls new to home visitation, suggesting that the change is not due to simple maturation. This analysis also confirmed that depressed parents had significantly lower HcL scores (4.3 vs. 4.0: $\mathrm{F}(1,1310)=33 ; P<.001)$ and $\mathrm{ScL}$ scores than their not-depressed counterparts $(4.3$ vs. 4.1 : $\mathrm{F}(1,1324)=$ 81; $P<.001)$.

\section{Discussion}

This study examined interactions between health literacy and depression among parents in enhanced home visitation. We used a combined database compiled from seven programs representing various models of home visitation. The programs were enhanced to promote parents' reflective skills.

\section{Depression}

One-fourth of parents were rated depressed at initiation of home visitation. This is below a recently reported range of $28.5-61 \%$ [11]. Similar to some previous reports [38], but in contrast to others [39], depressed parents in this sample were somewhat more likely to drop out of home visitation. 


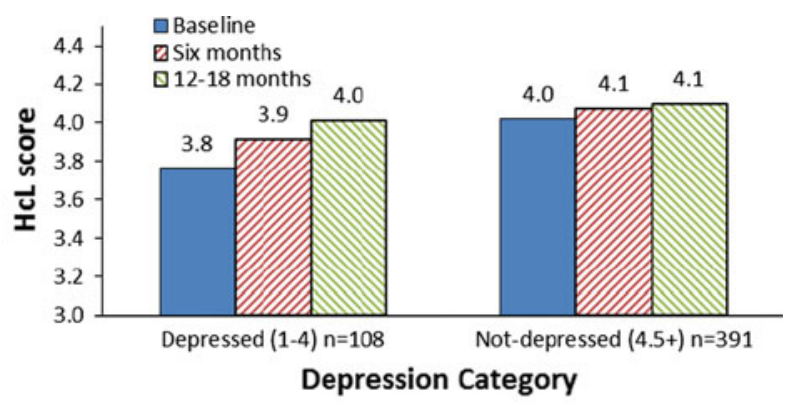

Depression: $F(1,497)=12 ; p<.001$

Time: $F(2,994)=30 ; p<.001$

Time * depression: $F(2,994)=8 ; p<.01$

Fig. 4 Changes in healthcare literacy from baseline to 6 months to 12-18 months for depressed versus not-depressed at intake

In this study, $14 \%$ of parents were persistently depressed throughout the service period. This rate is relatively low compared with several reports of up to $36 \%$ of parents in home visitation experiencing persistent depression [10,11].

The modest decrease in the overall rate of depression from 23 to $21 \%$ among parents in enhanced home visitation for 12-18 months is only part of the depression story for these parents. Among those in home visitation for 12-18 months, about half of those depressed at intake were in treatment (and 39\% of them recovered during service). Of those not in treatment, almost two-thirds either recovered during service $(38 \%)$ or moved into treatment $(25 \%)$. Among the 101 parents depressed throughout the service period, $69 \%$ were in treatment at least some of the time, compared with previous reports of $20 \%$ of persistent cases obtaining treatment [15]. Of parents who developed symptoms during service $(n=50), 62 \%$ obtained treatment $(n=31)$, exceeding a previously reported rate of a $13.5 \%$ for emergent cases [15]. The rate of untreated depression dropped from $11.9 \%$ at baseline to $8.5 \%$ after 12-18 months of service.

Several clinical trials found that home visitation alone imparted little or no benefit for maternal depression [10]. Our finding of a significant but small change in the depression rate seems consistent with this finding, considering the notably high proportion of depressed parents in this study who obtained treatment. Nontreatment has been attributed to stigma, lack of services, insurance, transportation and childcare [10]. That the participating programs also face these barriers suggests that the home visitors recognized at least the severe cases and were relatively successful in motivating and supporting parents to overcome multiple barriers to care. This indicates that parents increased their understanding and utilization of mental health services, demonstrating improved health literacy.

The relatively low incidence of new cases of depression during 12-18 months of service could suggest that home
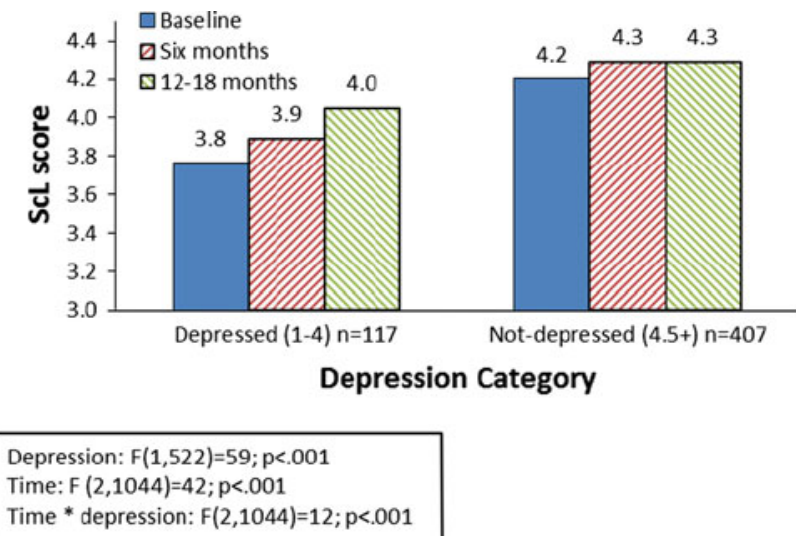

Fig. 5 Changes in selfcare literacy from baseline to 6 months to 12-18 months for depressed versus not-depressed at intake

visitors failed to recognize depression. However, Bugental and colleagues [40] found that a reflective approach similar to that used in the participating programs produced a significant reduction in depressive symptoms, suggesting that enhanced home visitation may have prevented the onset of depression in some and mitigated depression in others, or prevented moderate symptoms from escalating to persistent depression.

\section{Depression and Health Literacy}

After 12-18 months of home visitation with four assessments points, improved depression scores were positively correlated with improved use of information and services, and with enhanced self-management of personal and child health. Since, in this study, these factors are surrogate measures of health literacy, we posit that improvement in depression is positively correlated with improvement in health literacy.

Overall, depressed parents had lower health literacy than their not-depressed counterparts, supporting our hypothesis that depression impairs health literacy. But parents who were depressed at initiation of services made greater gains, opposing our hypothesis that depression impedes efforts to promote health literacy through home visitation. At intake, dramatic differences were observed between depressed and not-depressed parents in many of the individual items comprising the health literacy scales. However, these differences were either eliminated or reduced over the course of enhanced home visitation so that after 12-18 months parents who were depressed at intake were exhibiting health literacy skills similar to their not-depressed counterparts. Significant gains in health literacy were observed even where improvements in depression were modest, indicating that enhanced home visitation may help depressed parents overcome the influence of depression on health literacy separately from the effect on depression. 
Our findings confirm previous reports that a child's receipt of health services is established early in the child's life [5] and suggest that parents also may establish their personal health services utilization patterns during early parenting, including use of information, resources, social and health services, parent sick care and family planning. The study further confirmed that parental depression is associated with young children's receipt of care across a broad array of healthcare services [16], including wellchild care, sick-child care and immunizations. A new finding is that the influence of parental depression on use of child healthcare services can be reduced through enhanced home visitation.

In addition, this study demonstrates that viewing and measuring health literacy as a life skill that can be developed increases understanding of the ways people apply health literacy skills in their daily lives. That increased understanding suggests interventions to support effective use of information and services to enhance health. Future research should reframe health literacy as a capacitybuilding personal and community asset.

Further, this study demonstrates that enhanced home visitation is a promising practice for increasing disadvantaged parents' health literacy, and is especially promising for depressed parents who are at greater risk of poor health outcomes for themselves and their children. Future studies should test interventions that aim to improve both health literacy and depression in home visitation and other community settings, and assess impacts on personal and child health, healthcare utilization and clinical outcomes.

This study has important implications for MCH policy. It suggests an important role for home visitation in addressing health literacy and depression on a national scale. Findings demonstrate that depression does not preclude significant improvement in mothers' management of personal and child health and healthcare; and that home visitors can identify depressed parents and direct them to treatment. Findings further demonstrate that health literacy and depression involve complex interactions of multiple factors that are not readily visible in a clinical setting and support a medical home model that integrates home visitation to connect healthcare and home.

\section{Limitations and Strengths}

Depressed parents were significantly more likely than notdepressed parents to leave home visitation before the 1 -year assessment. The number of men in the sample was too small to comment on differential effects. The study did not assess the skills of the home visitations to act as change agents. The health literacy measures require further validation. The use of a matched comparison group, the longitudinal measurements, the large size and diversity of the study population, testing in the field, and the representation of multiple models of home visitation increase the validity and generalizability of findings.

\section{Conclusion}

Our findings demonstrate that parental health literacy is related to parental depression. The most important finding is that with enhanced home visitation vulnerable parents made significant gains in health literacy, especially in the face of depression.

Further, this study shows that a reflective model of home visitation practice can empower parents to better manage personal and child health and healthcare, even in the face of depression, thereby reducing the negative impacts of parental depression on family health and utilization of adult and child health services. Home visitation warrants further investigation as an existing infrastructure to support a national response to both health literacy and depression.

Acknowledgments This study was funded by the National Library of Medicine under contract N01-LM-6-3506 with the University of Washington.

Open Access This article is distributed under the terms of the Creative Commons Attribution Noncommercial License which permits any noncommercial use, distribution, and reproduction in any medium, provided the original author(s) and source are credited.

\section{References}

1. Abrams, M. A., Klass, P., \& Dreyer, B. P. (2009). Health literacy and children: Recommendations for action. Pediatrics, 124, S327-S331.

2. Pleasant, A. (2008). A second look at the health literacy of American adults and the national assessment of adult literacy (pp. 46-52). World Ed.

3. Yin, H. S., Johnson, M., Mendelsohn, A. L., Abrams, M. A., Sanders, L. M., \& Dreyer, B. P. (2009). The health literacy of parents in the United States: A nationally representative study. Pediatrics, 124, S289-S298.

4. Dewalt, D. A., \& Hink, A. (2009). Health literacy and child health outcomes: A systematic review of the literature. Pediatrics, 124, S265-S274.

5. Wolf, M. S., Wilson, E. A. H., Rapp, D. N., Waite, K. R., Bocchini, M. V., Davis, T. C., et al. (2009). Literacy and learning in healthcare. Pediatrics, 124, S275-S281.

6. Rudd, R. (2010). Mismatch between skills of patients and tools in use: Might literacy affect diagnoses and research? The Journal of Rheumatology, 37(5), 885-886.

7. England, M. J., \& Sim, L. J. (Eds.) (2009). Depression in parents, parenting, and children: Opportunities to improve identification, treatment, and prevention. (p. 1) Committee on Depression, Parenting Practices, and the Healthy Development of Children, National Research Council; Institute of Medicine. National Academy of Science.

8. Davé, S., Petersen, I., Sherr, L., \& Nazareth, I. (2010). Incidence of maternal and paternal depression in primary care. Archives of 
Pediatric Adolescent Medicine. Accessed online at www. archpediatrics.com.

9. Beck, C. T. (2007). Postpartum depression. American Journal of Nursing, 106(5), 40-50.

10. Ammerman, R. T., Putman, F. W., Bosse, N. R., Teeters, A. R., \& Van Ginkel, J. B. (2010). Maternal depression in home visitation: A systematic review. Aggression and Violent Behavior, 15, 191-200.

11. Ramos-Marcuse, F., Oberlander, S. E., Paps, M. A., McNary, S. W., Hurley, K. M., \& Black, M. M. (2009). Stability of maternal depressive symptoms among urban, low-income, African American adolescent mothers. Journal of Affective Disorders, 122, 68-75.

12. England, M. J., Sim, \& L. J. (Eds.) (2009). Depression in parents, parenting, and children: Opportunities to improve identification, treatment, and prevention (p. 5). Committee on Depression, Parenting Practices, and the Healthy Development of Children, National Research Council; Institute of Medicine. National Academy of Science.

13. England, M. J., \& Sim, L. J. (Eds.) (2009). Depression in parents, parenting, and children: Opportunities to improve identification, treatment and prevention. (p. 14) Committee on Depression, Parenting Practices, and the Healthy Development of Children, National Research Council; Institute of Medicine. National Academy of Science.

14. Sanders, L. M., Shaw, J. S., Guez, G., Baur, C., \& Rudd, R. E. (2009). Health literacy and child health promotion: Implications for research, clinical care and public policy. Pediatrics, 124, S306-S314.

15. Weiss, B. D., Francis, L., Senf, J. H., Heist, K., \& Hargraves, R. (2006). Literacy education as treatment for depression in patients with limited literacy and depression. Journal of General Internal Medicine, 21, 823-828.

16. Minkovitch, C. S., Strobino, D., Scharfstein, D., Hou, W., Miller, T., Mistry, K. B., et al. (2005). Maternal depressive symptoms and children's receipt of health care in the first three years of life. Pediatrics, 115, 306-314.

17. Weiss, B. D., Blanchard, J. S., McGee, D. L., Hart, G., Warren, B., Burgoon, M., et al. (1994). Illiteracy among medicaid recipients and its relationship to health care costs. Journal of Health Care for the Poor and Underserved, 5(2), 99-111.

18. Ammerman, R. T., Putman, F. W., Altaye, M., Chen, L., Holleb, L. J., Steven, J., et al. (2009). Changes in depressive symptoms in first time mothers in home visitation. Child Abuse and Neglect, 33(3), 127-138.

19. Stevens, J., Ammerman, R. T., Putnam, F. W., Gannon, T. A., \& Van Ginkel, J. B. (2005). Facilitators and barriers to engagement in home visitation: A qualitative analysis of maternal, provider and supervisor data. Journal of Aggression, Maltreatment and Trauma, 11, 75-93.

20. Kickbush, I. (2006). Health literacy: Skilling students for better health. Virtually Healthy, 3(41), 2. Available on line at http:// www.healthpromotion.cywhs.sa.gov.au/library/vh41.pdf.

21. Kickbush, I., Wait, S., \& Maag, D. (2005). Navigating health: The role of health literacy. www.emhf.org.

22. Nutbeam, D. (2008). The evolving concept of health literacy. Social Science \& Medicine, 67, 2072-2078.
23. Renkert, S., \& Nutbeam, D. (2001). Opportunities to improve maternal health literacy through ante-natal education: An exploratory study. Health Promotion International, 16, 381-388.

24. Organization, World Health. (1998). Health promotion glossary. Health Promotion International, 13(4), 349-364.

25. Ross, W., Culbert, A., Gasper, C., \& Kimmey, J. (2009). A theory-based approach to improving health literacy. St. Louis: Missouri Health Foundation Accessed January 10, 2011, at http://www.inter-disciplinary.net/wp-content/uploads/2009/06/ ross-paper.pdf.

26. Wollesen, L., \& Peifer, K. (2006). Life skills progression: An outcome and intervention planning instrument for use with families at risk. Baltimore, MD: Brookes.

27. Design Options for Home Visiting Evaluation TA. (2011). LIFE SKILLS PROGRESSION BRIEF: Information and Guidelines for Use in Meeting MIECHV Benchmarks. Administration for Children and Families. Available online at http://www.mdrc.org/dohve/ LSP_Brief.pdf.

28. Smith, S.A., \& Wollesen, L.A. (2004-2008). Beginnings guides life skills development curriculum implementation manual \& home visitors handbook. Seattle, WA: Practice Development Inc.

29. Slade, A. (2005). Parental reflective functioning: An introduction. Attachment \& Human Development, 7(3), 269-281.

30. Beck, A., Steer, R., \& Brown, G. (1996). BDI-II Manual. San Antonio: The Psychological Corporation.

31. Radloff, L. (1977). The CES-D scale: A self-report depression scale for research in the general population. Applied Psychological Measurement, 1, 385-401.

32. Cox, J., Holden, M., \& Sagovsky, R. (1987). Detection of postnatal depression. development of the 10-item Edinburgh postnatal depression scale. British Journal of Psychiatry, 150, 782-786.

33. Smith, S. A. (2009). Promoting health literacy: Concept, measurement \& intervention. Cincinnati, $\mathrm{OH}$ : Union Institute and University. Publication No. AAT 3375168.

34. Peerson, A., \& Saunders, M. (2009). Health literacy revisited: What do we mean and why does it matter? British Journal of Psychiatry, 24(3), 285-293.

35. Ishikawa, H., \& Yano, E. (2008). Patient health literacy and participation in the healthcare process. Health Expectations, 11, 113-122.

36. Pleasant, A., \& Kuruvilla, S. (2008). A tale of two literacies: Public health and clinical approaches to health literacy. Health Promotion International, 23(2), 152-159.

37. Adcock, R., \& Collier, D. (2001). Measurement validity: A shared standard for qualitative and quantitative research. American Political Science Review, 95, 529-546.

38. Bigatti, S. M., Cronan, T. A., \& Anaya, B. A. (2001). Effects of maternal depression on the efficacy of a literacy intervention program. Child Psychology \& Human Development, 32(2), $147-162$.

39. Damashek, A., Doughty, D., Ware, L., \& Silovsky, J. (2011). Predictors of client engagement and attrition in home-based child maltreatment prevention services. Child Maltreatment, 16(1), 9-20.

40. Bugental, D. B., Ellerson, P. C., Rainey, B., Lin, E. K., Koktovic, A., \& O'Hara, N. (2002). A cognitive approach to child abuse prevention. Journal of Family Psychology, 16, 243-258. 